Вип. 1, 2019

УДК 621.316.925

В. Г. Лисяк

Національний університет “Львівська політехніка", кафедра електроенергетики та систем управління,

Vladyslav.H.Lysiak@lpnu.ua

М. Й. Олійник

Національний університет “Львівська політехніка", кафедра електроенергетики та систем управління, Myhajlo.Ol@gmail.com

М. Б. Сабат

Національний університет “Львівська політехніка”, кафедра електроенергетики та систем управління,

Myroslav.B.Sabat@lpnu.ua

Ю. Л. Шелех

Національний університет “Львівська політехніка", кафедра електроенергетики та систем управління,

Yurii.L.Shelekh@1pnu.ua

\title{
МОДЕЛЮВАННЯ УСТАЛЕНИХ РЕЖИМІВ ЕЛЕКТРОМЕРЕЖІ ІЗ СИНХРОННИМ \\ ЕЛЕКТРОПРИВОДОМ ГІДРАВЛІЧНОГО НАВАНТАЖЕННЯ
}

https://doi.org/10.23939/sepes2019.01.036

С Лисяк В. Г., Олійник М. Й., Сабат М. Б., Шелех Ю. Л., 2019

Помпові станції, які забезпечують переміщення рідини трубопровідним транспортом, $є$ істотними споживачами електричної енергії. Перевитрати електроенергії внаслідок неоптимальних режимів роботи окремих потужних агрегатів чи неоптимальної кількості менш потужних агрегатів, які одночасно працюють, доволі значні й можуть суттєво впливати на загальне енергоспоживання. Перевитрати електроенергії на помпових станціях призводять також до відчутних її перевитрат в елементах електричних мереж.

Режими роботи потужних помпових станцій характеризуються повільною зміною координат у часі. У багатьох випадках це дає змогу обгрунтовано розглядати такі режими як сукупність квазістаціонарних станів, що змінюють один одного, без урахування впливу перехідних процесів. Проведений аналіз характеру типових режимів помпувальних агрегатів потужних помпових станцій та їхніх систем електропостачання обгрунтовує доцільність виокремлення досліджень усталених режимів. Переважна кількість наукових праць із моделювання й аналізу режимів роботи потужних помпових станцій стосується асинхронних електроприводних помпових агрегатів. Упровадження перспективного регульованого синхронного електроприводу на помпових станціях потребус створення відповідних засобів досліджень. 
Проводити натурні експерименти на діючих помпових станціях дорого, а доволі часто й недопустимо, оскільки під час експериментів необхідно порушувати їх безперервне функціонування. Тому моделювання процесів, які відбуваються на таких об'єктах, - здебілышого сдино можливий засіб їх безпечного дослідження, а також прогнозування безаварійних енергоощадних режимів і заходів. Показано, що синтез енергоефективних систем керування усталеними режимами таких об'єктів 3 метою підвищення їхньої енергоефективності зазвичай неможливий без комп'ютерного моделювання силової частини. Запропоновано математичну модель усталених режимів електромережі 3 частотно керованим синхронним електроприводом відцентрової помпи. Із використанням створеної моделі виконано низку тестових розрахунків усталених режимів. Наведено отримані графічні залежності основних координат від відносної витрати робочої рідини на вході трубопроводу.

Ключові слова: електромережа; синхронний двигун; реактивна потужність; частота; помпа; продуктивність; напір; математична модель.

\section{Постановка проблеми}

Бурові помпи, призначені для створення циркуляції промивної рідини і передавання гідравлічної енергії забійному двигуну, завдяки наявності розгалужених електричних мереж зазвичай урухомлюються потужними частотно керованими електродвигунами. Процес буріння свердловин, особливо в твердих породах, тривалий, внаслідок чого зростання напору помпи від нуля до максимального значення (залежно від глибини свердловини та потужності забійного двигуна) відбувається плавно упродовж багатьох діб [1-3]. Занурювальні відцентрові помпи 3 асинхронним чи синхронним електроприводом артезіанських водяних [4] свердловин також зазвичай працюють із практично сталими значеннями напору та продуктивності. На гідроакумулювальних станціях, де режим агрегатів циклічно змінюється із помпового (під час створення запасу води у водосховищах) на турбінний (під час витрачання запасеної води), потужність синхронних двигунів-генераторів становить сотні мегават [5]. Зміна режиму також відбувається плавно протягом тривалого часу. Координати режимів помпових станцій нафтогонів та водогонів із синхронним та асинхронним електроприводом помп, аналіз реєстрограм яких виконано у [6-9], теж доволі повільно змінюються у часі. Зокрема, поточне значення споживання води у міському водогоні водопостачання, за даними [8], змінюється не швидше, ніж 0,1 \% за секунду.

Виокремлення квазіусталених нормальних експлуатаційних режимів потужних помпувальних агрегатів та їхніх систем електропостачання дає змогу обгрунтовано застосовувати для аналізу засоби математичного моделювання усталених режимів.

\section{Актуальність дослідження}

Проводити фізичні експерименти на діючих потужних помпових станціях зазвичай дорого чи навіть неможливо [10] внаслідок необхідності порушувати їх безперервне функціонування. Тому цифрова модель силової частини як віртуальна складова повної гібридної моделі [11] такого об'єкта найчастіше залишається єдиним можливим засобом безпечного дослідження режимів та їхнього симулювання з метою синтезу енергоефективних систем керування.

\section{Формулювання мети та завдань статті}

Мета цієї роботи - обгрунтування та розроблення математичної моделі усталених режимів системи електропостачання з частотно керованим синхронним електроприводом відцентрової помпи.

\section{Аналіз останніх досліджень і публікацій}

Робіт щодо математичного моделювання, аналізу режимів та розроблення систем керування електроприводом помпових та компресорних станцій достатньо багато. Однак у переважній більшості 3 них увагу зосереджено на асинхронному електроприводі помпового навантаження (зокрема, у [12] подано математичну 
модель усталених режимів електропостачальної системи помпової станції з асинхронним електроприводом, а в [13] - систему керування усталеними режимами такого об’єкта). Менше праць, які стосуються синхронного електроприводу компресорних станцій, і лише деякі окремі - помпових. Моделювання й оптимізацію режимів синхронних двигунів потужних помпових станцій описано в роботі [14]. Механічна характеристика відцентрової помпи апроксимована квадратичною параболою (до складу виразу входять пусковий і номінальний моменти, сталий “коефіцієнт помпи” та квадрат частоти обертання). Розроблення схем електропостачання, математичний опис синхронного електродвигуна бурової помпи, опис експериментальних досліджень наведено в [3], однак гідравлічну підсистему в цій праці також подано гранично спрощено. У [15] розглянуто систему електропостачання помпової стації водопроводу із однофазним синхронним електроприводом помп, який живиться від сонячної електростанції; увагу зосереджено на питаннях безперебійності електропостачання. Усталені режими помпових агрегатів із синхронним електроприводом досліджено у роботі [16]; у ній зі збалансованим ступенем деталізації подано як відцентрову помпу, так і електродвигун, однак не розглянуто питання моделювання системи електропостачання.

\section{Виклад основного матеріалу}

Узагальнену структурну схему електропостачання синхронного двигуна, який приводить у дію відцентрову помпу, зображено на рис. 1.

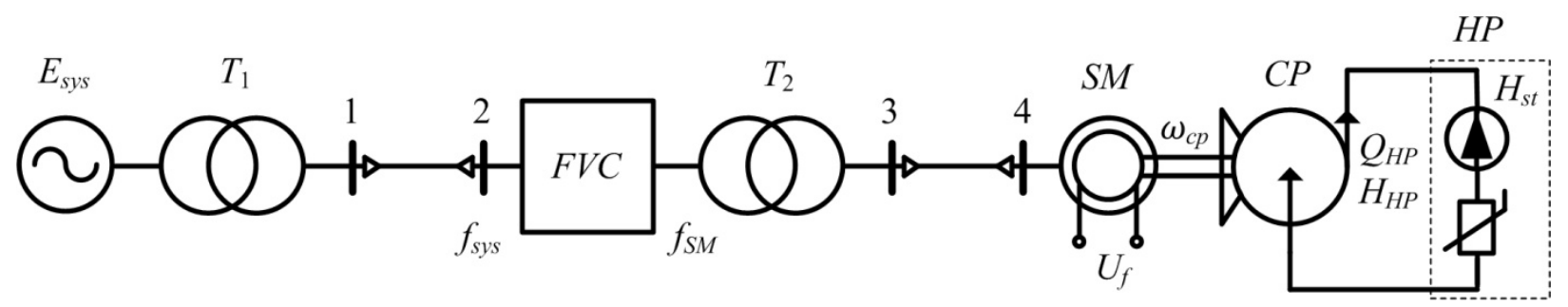

Рис. 1. Структурна схема електроживлення синхронного двигуна із відцентровою помпою

В усталеному режимі відцентрова помпа $C P$ створює напір $H_{H P}$ робочої рідини на вході в гідравлічний трубопровід $H P$ зі статичним протинапором $H_{s t}$, підтримуючи споживання рідини на рівні $Q_{H P}$. Обертання робочого колеса помпи 3 кутовою швидкістю $\omega_{C P}$ здійснює синхронний двигун SM, вал якого жорстко з'єднаний із валом робочого колеса. Необхідна для забезпечення заданого гідравлічного режиму агрегатом двигун-помпа напруга $U_{s}$ живлення статора синхронного двигуна із частотою $f_{s}$ формується за допомогою перетворювача частоти й напруги $F V C$. У загальному випадку живлення двигуна може здійснюватись по кабельній лінії 3-4 через додатковий трансформатор $T_{2}$, на первинну обвитку якого подається напруга $U_{2 F V C} 3$ виходу $F V C$. На вхід перетворювача частоти й напруги подається напруга $U_{1 F V C}$ промислової частоти $f$ по лінії $1-2$ від живильного трансформатора $T_{1}$ системи електропостачання від електроенергетичної системи живлення, яка має ЕРС $E_{s y s}$.

Згідно з цією схемою формується математична модель, яка складається із рівнянь гідравлічного трубопроводу, помпи, двигуна, трансформаторів, частотного перетворювача, ліній електропередачі, електроенергетичної системи живлення з урахуванням гідравлічних і електричних сполучень, а також - механічних та енергетичних зв'язків. Перетворену модель помпи отримано з іï уточненої моделі [17], розробленої на основі електрогідродинамічної аналогії. Усі рівняння моделі записано у відносних одиницях у системі обертових жорстко зв'язаних із робочим колесом помпи ортогональних $d-q$ координат (у цьому випадку, щоб запис не був дуже громіздкий, символ * у позначенні відносних одиниць пропущено):

- гідравлічний трубопровід:

$$
\sqrt{H_{H P d}^{2}+H_{H P d}^{2}}-H_{s t}-\left(1-H_{s t}\right)\left(Q_{H P d}^{2}+Q_{H P q}^{2}\right)=0
$$


- відцентрова помпа (з урахуванням залежності параметрів від кутової швидкості):

$$
\begin{aligned}
& \left(R_{0}+R_{1}\right) Q_{\Sigma d}-\left(X_{0}+X_{1}\right) Q_{\Sigma q}-R_{0} Q_{H P d}+X_{0} Q_{H P q}=H_{0 d}, \\
& \left(X_{0}+X_{1}\right) Q_{\Sigma d}+\left(R_{0}+R_{1}\right) Q_{\Sigma q}-X_{0} Q_{H P d}-R_{0} Q_{H P q}=H_{0 q}, \\
& R_{0} Q_{\Sigma d}-X_{0} Q_{\Sigma q}-\left(R_{0}+R_{2}\right) Q_{H P d}+\left(X_{0 e i}+X_{2 e i}\right) Q_{H P q}=H_{H P d}, \\
& X_{0} Q_{\Sigma d}+R_{0} Q_{\Sigma q}-\left(X_{0}+X_{2}\right) Q_{H P d}-\left(R_{0}+R_{2}\right) Q_{H P q}=H_{H P q}, \\
& \sqrt{H_{0 d}^{2}+H_{0 q}^{2}}-H_{0 n o m} \omega_{c p}^{2}=0, \\
& Q_{H P d} H_{H P q}-Q_{H P q} H_{H P d}=0, \\
Q_{H P d}- & \sqrt{Q_{H P d}^{2}+Q_{H P q}^{2}} \cos \Psi_{0 Q H}=0 ;
\end{aligned}
$$

- синхронний двигун (з урахуванням залежності параметрів від частоти):

$$
\begin{gathered}
R_{s} I_{s d}-\omega_{c p}\left(X_{s} I_{s q}+\Psi_{\delta q}\right)=U_{s d}, \\
R_{s} I_{s q}+\omega_{c p}\left(X_{s} I_{s d}+\Psi_{\delta d}\right)=U_{s q}, \\
R_{m S M}\left(\Psi_{\delta d}, \Psi_{\delta q}\right) \Psi_{\delta d}-\omega_{c p} \Psi_{\delta q} / R_{a}-I_{s d}=I_{f}, \\
R_{m S M}\left(\Psi_{\delta d}, \Psi_{\delta q}\right) \Psi_{\delta q}+\omega_{c p} \Psi_{\delta d} / R_{a}-I_{s q}=0, \\
U_{s q} I_{s d}-U_{s d} I_{s q}=\left(U_{s d} I_{s d}+U_{s q} I_{s q}\right) \operatorname{tg} \varphi_{S M} ;
\end{gathered}
$$

- енергетичний зв'язок між помпою та двигуном:

$$
H_{0 d} Q_{\Sigma d}+H_{0 q} Q_{\Sigma q}=\omega_{c p}\left(\Psi_{\delta d} I_{s q}-\Psi_{\delta q} I_{s d}\right)
$$

- кабельна лінія 3-4 електропередачі (з урахуванням залежності зарядної потужності від частоти):

$$
\begin{aligned}
& r_{34}^{2} I_{2 d T_{2}}-r_{34}\left(U_{2 d T_{2}}-U_{s d}\right)-0,5 \cdot \omega_{c p} b_{34} r_{34}^{2} U_{2 q T_{2}}=0, \\
& r_{34}^{2} I_{2 q T_{2}}-r_{34}\left(U_{2 q T_{2}}-U_{s q}\right)+0,5 \cdot \omega_{c p} b_{34} r_{34}^{2} U_{2 d T_{2}}=0, \\
& r_{34}^{2} I_{s d}-r_{34}\left(U_{2 d T_{2}}-U_{s d}\right)+0,5 \cdot \omega_{c p} b_{34} r_{34}^{2} U_{s q}=0, \\
& r_{34}^{2} I_{s q}-r_{34}\left(U_{2 q T_{2}}-U_{s q}\right)-0,5 \cdot \omega_{c p} b_{34} r_{34}^{2} U_{s d}=0 ;
\end{aligned}
$$

- $\quad$ трансформатор $T_{2}$ (з урахуванням залежності параметрів від частоти):

$$
\begin{aligned}
& -R_{2 T_{2}} I_{2 d T_{2}}+\omega_{c p}\left(X_{2 T_{2}} I_{2 q T_{2}}+\Psi_{1 q T_{2}}\right)=k_{T_{2}} U_{2 d T_{2}}, \\
& -R_{2 T_{2}} I_{2 q T_{2}}-\omega_{c p}\left(X_{2 T_{2}} I_{2 d T_{2}}-\Psi_{1 d T_{2}}\right)=k_{T_{2}} U_{2 q T_{2}}, \\
& R_{1 T_{2}} I_{1 d T_{2}}-\omega_{c p}\left(X_{1 T_{2}} I_{1 q T_{2}}+\Psi_{1 q T_{2}}\right)=U_{1 d T_{2}}, \\
& R_{1 T_{2}} I_{1 q T_{2}}+\omega_{c p}\left(X_{1 T_{2}} I_{1 d T_{2}}+\Psi_{1 d T_{2}}\right)=U_{1 q T_{2}}, \\
& R_{m T_{2}}\left(\Psi_{1 d T_{2}}, \Psi_{l q T_{2}}\right) \Psi_{1 d T_{2}}-\omega_{c p} G_{T_{2}} \Psi_{1 q T_{2}}+I_{2 d T_{2}}=I_{1 d T_{2}}, \\
& R_{m T_{2}}\left(\Psi_{1 d T_{2}}, \Psi_{l q T_{2}}\right) \Psi_{1 q T_{2}}+\omega_{c p} G_{T_{2}} \Psi_{1 d T_{2}}+I_{2 q T_{2}}=I_{1 q T_{2}} ;
\end{aligned}
$$

- перетворювач частоти й напруги:

$$
\begin{aligned}
& \left(U_{1 F V C d} I_{1 F V C d}+U_{1 F V C q} I_{1 F V C q}\right)-\Delta P_{F V C}=U_{1 d T_{2}} I_{1 d T_{2}}+U_{1 q T_{2}} I_{1 q T_{2}}, \\
& \left(U_{1 F V C q} I_{1 F V C d}-U_{1 F V C d} I_{1 F V C q}\right)-\Delta Q_{F V C}=U_{1 q T_{2}} I_{1 d T_{2}}-U_{1 d T_{2}} I_{1 q T_{2}} ;
\end{aligned}
$$

- кабельна лінія 1-2 електропередачі:

$$
r_{12}^{2} I_{1 d}-r_{12}\left(U_{1 d}-U_{1 F V C d}\right)-0,5 \cdot b_{12} r_{12}^{2} U_{1 q}=0
$$




$$
\begin{aligned}
& r_{12}^{2} I_{1 q}-r_{12}\left(U_{1 q}-U_{1 F V C q}\right)+0,5 \cdot b_{12} r_{12}^{2} U_{1 d}=0, \\
& r_{12}^{2} I_{1 F V C d}-r_{12}\left(U_{1 d}-U_{1 F V C d}\right)+0,5 \cdot b_{12} r_{12}^{2} U_{1 F V C q}=0, \\
& r_{12}^{2} I_{1 F V C q}-r_{12}\left(U_{1 q}-U_{1 F V C q}\right)-0,5 \cdot b_{12} r_{12}^{2} U_{1 F V C d}=0 ;
\end{aligned}
$$

- трансформатор $T_{1}$ :

$$
\begin{aligned}
& -R_{2 T_{1}} I_{1 d}+X_{2 T_{1}} I_{1 q}+\Psi_{1 q T_{1}}=k_{T_{1}} U_{1 d}, \\
& -R_{2 T_{1}} I_{1 q}-X_{2 T_{1}} I_{1 d}+\Psi_{1 d T_{1}}=k_{T_{1}} U_{1 q}, \\
& R_{1 T_{1}} I_{1 d T_{1}}-X_{1 T_{1}} I_{1 q T_{1}}-\Psi_{1 q T_{1}}=U_{1 d T_{1},}, \\
& R_{1 T_{1}} I_{1 q T_{1}}+X_{1 T_{1}} I_{1 d T_{1}}+\Psi_{1 d T_{1}}=U_{1 q T_{1}}, \\
& R_{m T_{1}}\left(\Psi_{1 d T_{1}}, \Psi_{1 q T_{1}}\right) \Psi_{1 d T_{1}}-G_{T_{1}} \Psi_{1 q T_{1}}+I_{1 d}=I_{1 d T_{1}}, \\
& R_{m T_{1}}\left(\Psi_{1 d T_{1}}, \Psi_{1 q T_{1}}\right) \Psi_{l q T_{1}}+G_{T_{1}} \Psi_{1 d T_{1}}+I_{1 q}=I_{1 q T_{1}} ;
\end{aligned}
$$

- електроенергетична система живлення:

$$
\begin{aligned}
& E_{s y s d}-R_{s y s} I_{1 d T_{1}}+X_{s y s} I_{1 q T_{1}}=U_{1 d T_{1}}, \\
& E_{s y s q}-R_{s y s} I_{1 q T_{1}}-X_{s y s} I_{1 d T_{1}}=U_{1 q T_{1}},
\end{aligned}
$$

де $\omega_{C P}$ - колова частота обертання спільного вала двигуна й помпи; $H_{0}, Q_{\Sigma}, H_{H P}, Q_{H P}$ - поточні

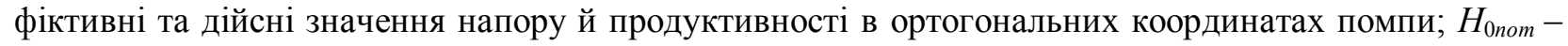
номінальний фіктивний напір помпи; $\Psi_{0 Q H}$ - початкова фаза зображального вектора напруги продуктивності помпи (довільна); $R_{0}, R_{1}, R_{2}, X_{0}, X_{1}, X_{2}$ - дисипативні та індуктивні гідравлічні опори перетвореної моделі помпи [19]; $R_{s}, X_{s}, X_{\sigma}, X_{s a}$ - активний та індуктивний опори якоря, а також індуктивні опори розсіяння та намагнічування двигуна; $\varphi_{S M}-$ кут між векторами струму та напруги обвитки якоря двигуна; $R_{a}$ - резистанс, який враховує втрати активної енергії у сталевому осерді двигуна; $R_{m S M}\left(\Psi_{\delta d}, \Psi_{\delta q}\right)=\left(0,82+0,148 \cdot\left(\psi_{\delta d}^{2}+\psi_{\delta q}^{2}\right)+0,044 \cdot\left(\psi_{\delta d}^{2}+\psi_{\delta q}^{2}\right)^{4}\right) /\left(X_{\sigma}+X_{a}\right)-$ нелінійний статичний магнітний опір головного магнітного кола двигуна; $R_{1 T}, R_{2 T}, X_{1 T}, X_{2 T}$ - активні опори та індуктивні опори розсіяння обвиток трансформаторів; $G_{T}$ - поперечна провідність, яка враховує втрати активної потужності в магнітопроводі трансформатора; $b_{T}$ - поперечна магнітна провідність трансформатора; $R_{m T}\left(\Psi_{\delta 1 d T}, \Psi_{\delta 1 q T}\right)=b_{T}\left(0,527176 \cdot\left(\psi_{\delta 1 d T}^{2}+\psi_{\delta 1 q T}^{2}\right)+0,231535 \cdot\left(\psi_{\delta 1 d T}^{2}+\psi_{\delta 1 q T}^{2}\right)^{3}+\right.$ $\left.+0,241290 \times\left(\psi_{\delta 1 d T}^{2}+\psi_{\delta 1 q T}^{2}\right)^{5}\right)-$ нелінійний статичний магнітний опір намагнічування трансформатора; $\Delta P_{F V C}, \Delta Q_{F V C}$ - втрати активної та реактивної потужностей у перетворювачі напруги й частоти; $r_{12}, r_{34}, b_{12}, b_{34}$ - параметри П-подібних заступних схем кабельних ліній електропередачі; $R_{S Y S}, X_{S Y S}$ - еквівалентні активний та індуктивний опори, а також ЕРС електроенергетичної системи живлення; $U, I, \Psi$ - напруги, струми, ЕРС та потокозчеплення в ортогональних координатах режиму елементів структурної схеми, що на рис. 1.

Для однозначного розв'язання системи рівнянь (1)-(38) іiі необхідно доповнити двома рівняннями керування електромагнітними режимами синхронного двигуна. В цьому випадку (для прикладу) керування здійснюється підтриманням сталого заданого значення $\Psi_{g}=$ const потокозчеплення, а також ортогональності зображальних векторів потокозчеплення та струму якоря. У цьому режимі електромагнітний момент двигуна набуває максимально можливих значень:

$$
\begin{aligned}
& \psi_{\delta d_{i}}^{2}+\psi_{\delta q_{i}}^{2}=\psi_{g}, \\
& \Psi_{\delta d_{i}} I_{s d_{i}}+\Psi_{\delta q_{i}} I_{s q_{i}}=0 .
\end{aligned}
$$


Пошук нульових наближень для розв'язання нелінійної системи рівнянь (1)-(40) математичної моделі здійснюється диференційним методом у формі $h$-характеристик аналогічно, як у [12].

Для тестових розрахунків вибрано: трансформатори ТМ-1600/10 $\left(k_{T 2}=1\right)$; двигун СДТП-16002УХЛ4; відцентрову помпу НМ-1250-260; робочу рідину - воду. Розрахунок режимів виконано для розділеного на 50 однакових інтервалів діапазону витрати робочої рідини на вході гідравлічного трубопроводу в межах 0,0-1,2 номінального значення для вибраної помпи. Рівняння (1) із нульовим статичним протинапором для випадку частотно керованого двигуна 3 метою підтримання сталого (незалежного від продуктивності) напору на вході трубопроводу перетворюється на таке:

$$
H_{H P d}^{2}+H_{H P d}^{2}=1 \text {. }
$$

На рис. 2-11 наведено отримані залежності основних координат усталених режимів від відносної витрати робочої рідини на вході трубопроводу (напруги і струми зведено до напруги $U_{\text {snom }}$ ).

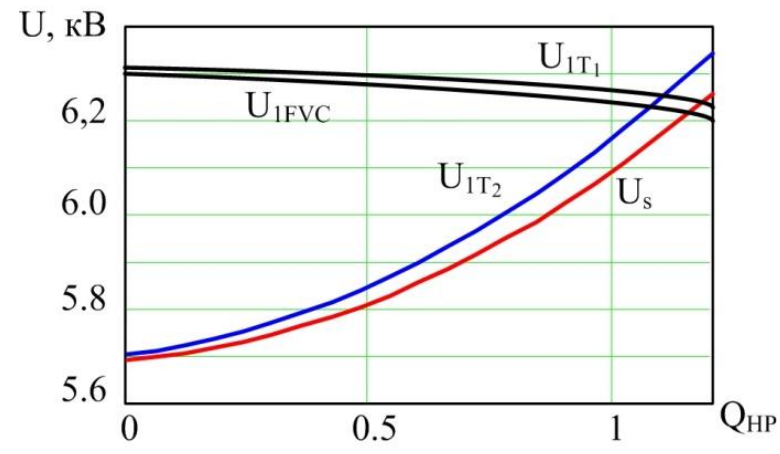

Рис. 2. Напруги вузлів схеми

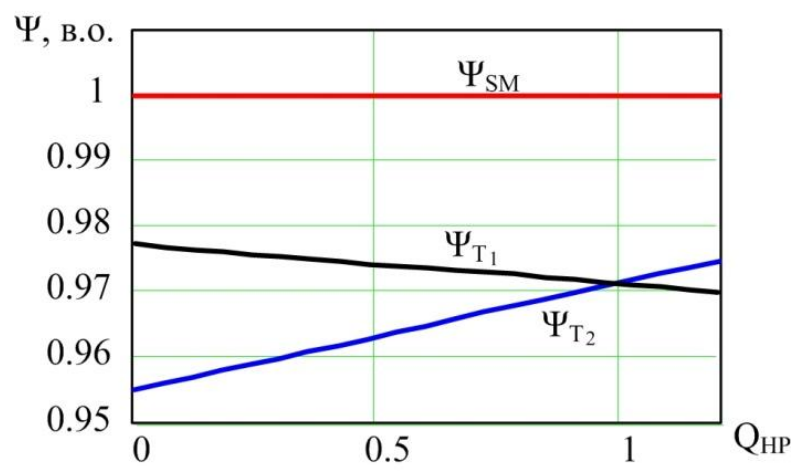

Рис. 4. Відносні потокозчеплення

$\mathrm{W}$, кВт·год/ $\mathrm{M}^{3}$

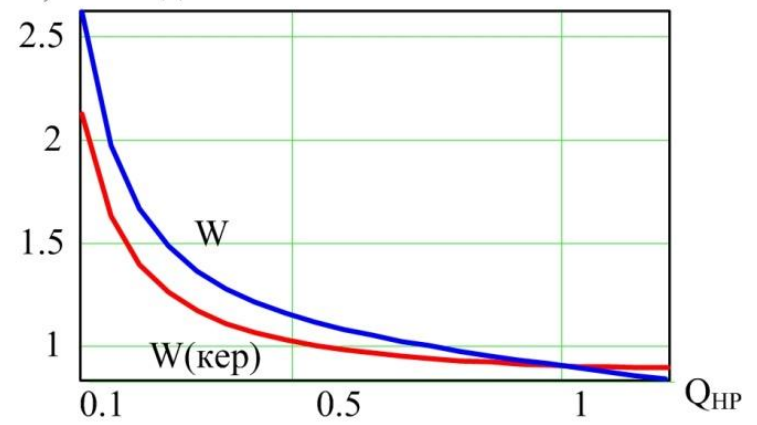

Рис. 6. Питомі витрати активної електроенергіі

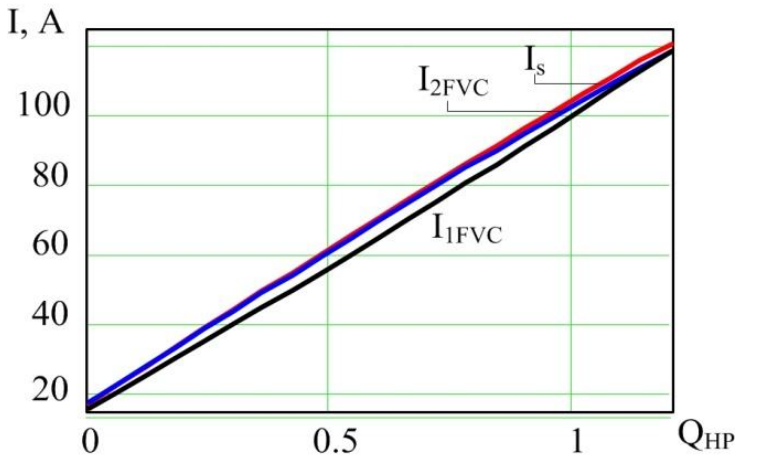

Рис. 3. Струми віток схеми

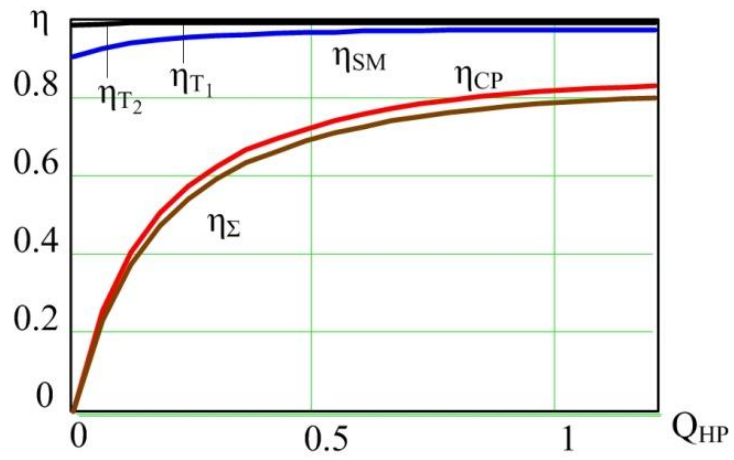

Рис. 5. Коефіцієнти корисної діï

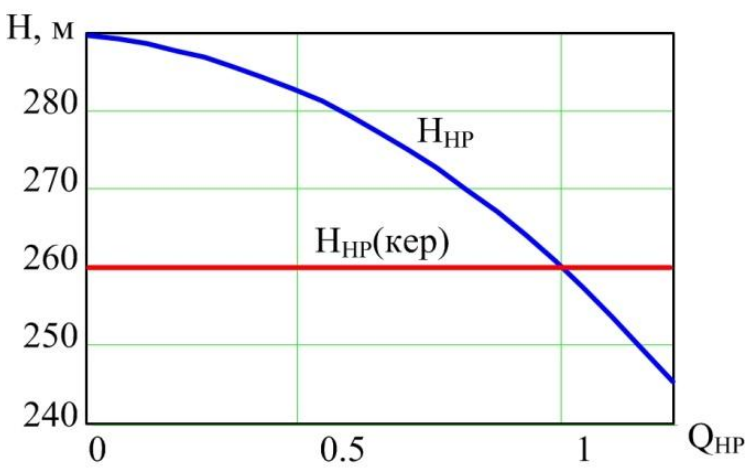

Рис. 7. Напір на вході трубопроводу

3 метою порівняння керованого режиму синхронного двигуна 3 некерованим на рис. 6 i 7 наведено залежності одночасно для двох режимів: керованого та некерованого (за номінальної 
частоти обертання), коли гідравлічний трубопровід описується рівнянням (1) із нульовим статичним протинапором. Зазначимо, що, оскільки витратою агрегату керувати неможливо (напір агрегату залежить лише від його витрати), відцентрова помпа працює за паспортною напірновитратною характеристикою (рис. 7).

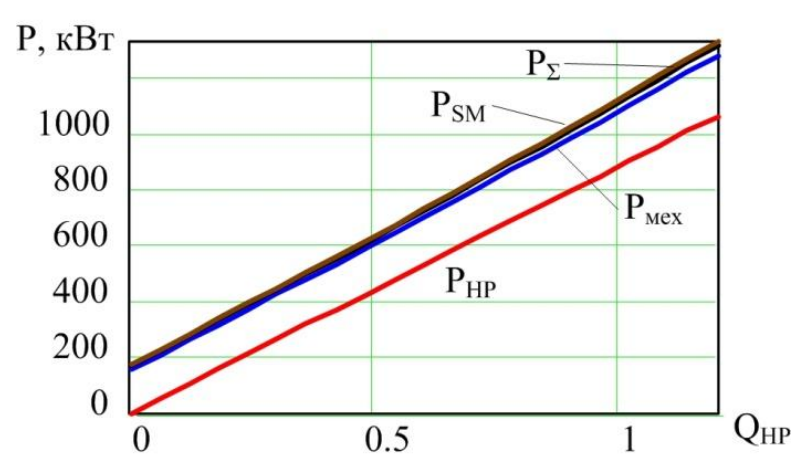

Рис. 8. Механічні та активні електричні потужності

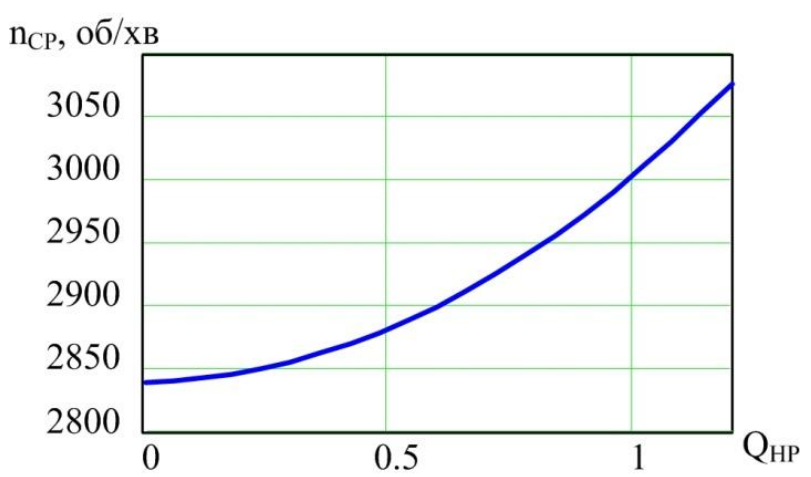

Рис. 10. Частота обертання спільного вала

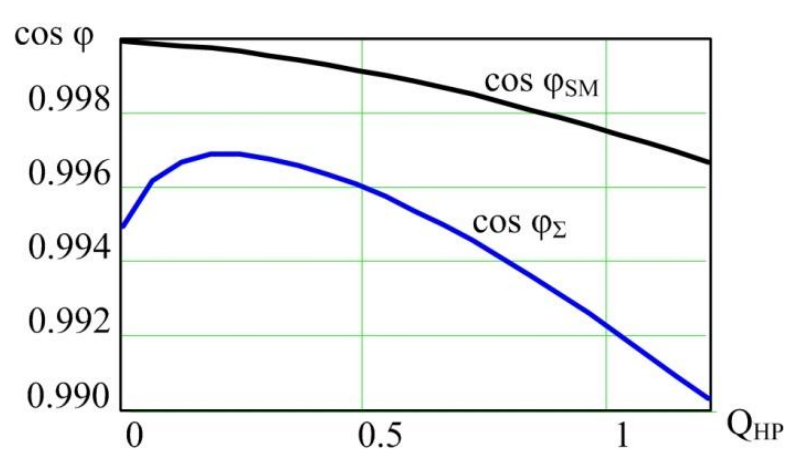

Рис. 9. Коефіиієнти потужності

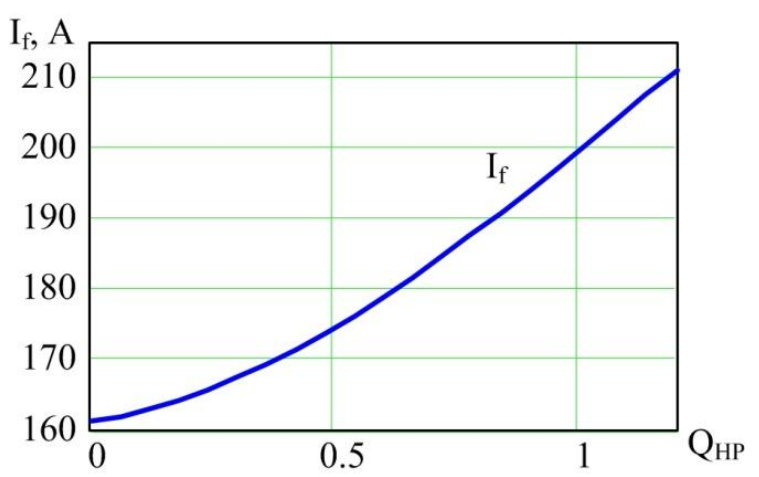

Рис. 11. Струм збудження СД

\section{Висновки}

Запропонована математична модель дає змогу здійснювати комплексний розрахунок усталених режимів потужних помпувальних агрегатів із синхронним електроприводом та їхніх систем електропостачання з урахуванням внутрішніх параметрів та взаємного впливу підсистем різної фізичної природи. Здійснено тестові розрахунки усталених режимів як з некерованим, так і 3 частотно керованим агрегатом. Приклад отриманих графічних залежностей низки основних координат режиму від витрати робочої рідини свідчить про широкі можливості застосування створеної моделі для аналізу усталених режимів роботи систем електропостачання синхронного електроприводного гідравлічного навантаження.

\section{Перспективи подальших досліджень}

На наступному етапі заплановано розроблення динамічної моделі усталених режимів електромережі із синхронним електроприводом гідравлічного навантаження.

\section{Список використаних джерел}

1. Шабанов В. А., Никулин О. В. Векторное регулирование момента синхронного электродвигателя бурового насоса // Известия ВУЗов. Проблемы энергетики. 2011. № 9-10. URL: https://cyberleninka.ru/article/n/vektornoeregulirovanie-momenta-sinhronnogo-elektrodvigatelya-burovogo-nasosa (дата обращения: 27.05.2019).

2. Шабанов В. А., Никулин О. В. Модель синхронного двигателя бурового насоса в среде Симулинк // Электротехнические комплексы и системы: меж вуз. научн. сб. Уфа: УГАТУ, 2009. С. 70-75.

3. Никулин О. В. Разработка и исследование частотно-регулируемого синхронного электропривода 
бурового насоса: монография. Москва: Русайнс, 2017. 152 с.

4. Машнев А. Е. Экономия электроэнергии при водоснабжении большого города / А. Е. Машнев, И.В.Бовдуй // Вестник Нац. техн. ун-та "Харьковский политехнический институт”. 2008. Вып. 30. С. $507-$ 508 .

5. Хакимуллин Б. Р., Багаутдинов И. З. Гидроаккумулирующие электростанции // Инновационная наука. 2016. № 4-3 (16). URL: https://cyberleninka.ru/article/n/gidroakkumuliruyuschie-elektrostantsii-1 (дата обращения: 17.05.2019).

6. Реалізація енергозберігаючої системи електроприводу для багатопомпувальної станції дПВ3 / В. П. Борисенко, С. В. Григор'єв, В. П. Овсянніков О. В. Головін // ХІІІ Международная науч.-техн. конф. “Машиностроение и техносфера XXI века": сб. тр. в 2 т. Севастополь, 2006. Т. 1. С. 138-140.

7. Браславский И. Я. Энергосберегающий асинхронный электропривод / И. Я. Браславский, 3. Ш. Ишматов, В. Н. Поляков. М.: Академия, 2004. 256 с.

8. Куцик А. С. Математична модель системи "частотно-керований електропривод - насос водопровідна мережа" / А. С. Куцик, А. О. Лозинський, О. Ф. Кінчур // Вісник Національного університету “Львівська політехніка”. Електроенергетичні та електромеханічні системи. 2015. № 834. С. 48-55.

9. Николаев В. Г. Энергосберегающие способы управления лопастными насосными агрегатами в системах водоснабжения при нестационарной нагрузке [Електронний ресурс] // Сантехника. Рубрика "Водоснабжение" : журнал. 2006. № 4. С. 22-28.

10. Федоров А. В. Применение источников бесперебойного питания в энергетических установках промышленных объектов в нефтегазовой отрасли / А. В. Федоров, С. В. Бабурин, А. Н. Махалин // Наука и техника в газовой промышленности, 2014.№ 2. С. 70-74.

11. K. Ou et al., "MMC-HVDC Simulation and Testing Based on Real-Time Digital Simulator and Physical Control System", in IEEE Journal of Emerging and Selected Topics in Power Electronics, vol. 2, no. 4, pp. 11091116, Dec. 2014.

12. Лисяк В. Г. Узагальнена математична модель усталених режимів електропостачальної системи помпової станції / В. Г. Лисяк, П. Ф. Гоголюк // Праці Інституту електродинаміки Національної академії наук України. - 2015. - Вип. 42. - С. 22-26.

13. Paranchuk Y. S., Lysiak V. H. Energy efficient power supply system and automatic control of the complex “power supply - pumping station” modes. Naukovyi Visnyk NHU, 2018, № 3, pp. 115-124.

14. Абдулла Ибрагим, Мослем Аль-Удейнат. Моделирование и оптимизация режимов работы синхронных электродвигателей крупных насосных станций: автореф. дис. на соискание науч. степени канд. техн. наук: спец. 05.09.03 “Электротехнические комплексы и системы” / Ташкентский гос. техн. ун-т им. Абуракхмана Беруни. Ташкент, 1998. 22 с.

15. B. Singh and S. Murshid, "A Grid-Interactive Permanent-Magnet Synchronous Motor-Driven Solar WaterPumping System”, in IEEE Transactions on Industry Applications, vol. 54, no. 5, pp. 5549-5561, Sept.-Oct. 2018.

16. Gogolyuk P., Lysiak V., Grinberg I. Mathematical Modeling Of A Synchronous Motor And Centrifugal Pump Combination In Steady State [Electronic resource], in: IEEE PES Power Systems Conference \& Exposition, 10-13 October 2004, New York City, NY : Conference Publications, 2004, Vol. 3, pp. 1444-1448.

17. Kostyshyn, V. S. Simulation of performance characteristics of centrifugal pumps by the electrohydrodynamic analogy method / V. S. Kostyshyn, P. O. Kurlyak, in : Journal of Hydrocarbon Power Engineering, 2015, vol. 2, № 1, pp. 24-31.

18. Лисяк В. Г. Математичне моделювання усталених режимів електропостачальної системи помпової станції // Технічна електродинаміка.К., 2008. № 2. С. 43-50.

19. Lysiak V., Oliinyk M. Modeling of Hydraulic Load of Electric Drive in Electrical Complex of Pumping Station. Energy Eng. Control Syst., 2018, Vol. 4, No. 1, pp. 31-36.

\section{References}

1. Shabanov V. A., Nykulyn O. V. Vektornoe rehulyrovanye momenta synkhronnoho эlektrodvyhatelia burovoho nasosa // Yzvestyia VUZov. Problemb эnerhetyky. 2011. No. 9-10. URL: https://cyberleninka.ru/article/n/vektornoeregulirovanie-momenta-sinhronnogo-elektrodvigatelya-burovogo-nasosa (data obrashchenyia: 27.05.2019). [in Russian].

2. Shabanov V. A., Nykulyn O. V. Model synkhronnoho dvyhatelia burovoho nasosa v srede Symulynk // Эlektrotekhnycheskye kompleksы y systemb. Mezhvuzovskyi nauchnbi sbornyk. Ufa: UHATU, 2009. S. 70-75. [in Russian].

3. Razrabotka y yssledovanye chastotno-rehulyruemoho synkhronnoho эlektropryvoda burovoho nasosa: monohrafyia / O.V. Nykulyn. Moskva: Rusains, 2017. 152 s. [in Russian].

4. Mashnev A. E. Эkonomyia эlektroэnerhyy pry vodosnabzhenyy bolshoho horoda / A. E. Mashnev, 


\section{В. Г. Лисяк, М. Й. Олійник, М. Б. Сабат, Ю. Л. Шелех}

Y. V. Bovdui // Vestnyk Nats. tekhn. un-ta "Kharkovskyi polytekhnycheskyi ynstytut". 2008. Vыp. 30. S. 507-508 [in Russian].

5. Khakymullyn B. R., Bahautdynov Y. Z. Hydroakkumulyruiushchye эlektrostantsyy // Ynnovatsyonnaia nauka. 2016. No. 4-3 (16). URL: https://cyberleninka.ru/article/n/gidroakkumuliruyuschie-elektrostantsii-1 (data obrashchenyia: 17.05.2019) [in Russian].

6. Borysenko V. P. Realizatsiia enerhozberihaiuchoi systemy elektropryvodu dlia bahatopompuvalnoi stantsii DPVZ / V. P. Borysenko, S. V. Hryhoriev, V. P. Ovsiannikov, O. V. Holovin // XIII mezhdunarodnaia nauch.-tekhn. konf. "Mashynostroenye y tekhnosfera XXI veka": sb. tr. v 2 t. Sevastopol, 2006. T. 1. S. 138-140. [in Russian].

7. Braslavskyi Y. Ya. Эnerhosberehaiushchyi asynkhronnui эlektropryvod / Y. Ya. Braslavskyi, Z. Sh. Yshmatov, V. N. Poliakov. M.: Akademyia, 2004. - 256 s. [in Russian].

8. Kutsyk A. S. Matematychna model systemy "chastotno-kerovanyi elektropryvod - nasos - vodoprovidna merezha" / A. S. Kutsyk, A. O. Lozynskyi, O. F. Kinchur // Visnyk Natsionalnoho universytetu "Lvivska politekhnika". Elektroenerhetychni ta elektromekhanichni systemy. 2015. No. 834. S. 48-55 [in Ukrainian].

9. Nykolaev V. H. Эnerhosberehaiushchye sposobы upravlenyia lopastnыmy nasosnumy ahrehatamy v systemakh vodosnabzhenyia pry nestatsyonarnoi nahruzke [Elektronnyi resurs] // Santekhnyka. Rubryka "Vodosnabzhenye" : zhurnal. 2006. No. 4. S. 22-28. [in Russian].

10. Fedorov A. V. Prymenenye ystochnykov bespereboinoho pytanyia $\mathrm{v}$ эnerhetycheskykh ustanovkakh prombshlennыkh obъektov v neftehazovoi otrasly/ A. V. Fedorov, S. V. Baburyn, A. N. Makhalyn // Nauka y tekhnyka v hazovoi prombshlennosty, 2014. No2. S. 70-74. [in Russian].

11. K. Ou et al., "MMC-HVDC Simulation and Testing Based on Real-Time Digital Simulator and Physical Control System", in IEEE Journal of Emerging and Selected Topics in Power Electronics, vol. 2, no. 4, pp. 11091116, Dec. 2014.

12. Lysiak V. H. Uzahalnena matematychna model ustalenykh rezhymiv elektropostachalnoi systemy pompovoi stantsii / V. H. Lysiak, P. F. Hoholiuk // Pratsi Instytutu elektrodynamiky Natsionalnoi akademii nauk Ukrainy. 2015. Vyp. 42. S. 22-26. [in Ukrainian].

13. Paranchuk Y. S., Lysiak V. H. Energy efficient power supply system and automatic control of the complex "power supply - pumping station" modes. Naukovyi Visnyk NHU, 2018, No. 3, pp. 115-124.

14. Abdulla Ybrahym, Moslem Al-Udeinat. Modelyrovanye y optymyzatsyia rezhymov rabotb synkhronnыkh эlektrodvyhatelei krupnыkh nasosnыkh stantsyi: avtoref. dys. na soyskanye nauch. stepeny kand. tekhn. nauk : spets. 05.09.03 "Эlektrotekhnycheskye kompleksы у systemb” / Tashkentskyi Hosudarstvennui tekhnycheskyi unyversytet ym. Aburakkhmana Beruny. Tashkent, 1998. 22 s. [in Russian].

15. B. Singh and S. Murshid, "A Grid-Interactive Permanent-Magnet Synchronous Motor-Driven Solar Water-Pumping System", in IEEE Transactions on Industry Applications, vol. 54, no. 5, pp. 5549-5561, Sept.-Oct. 2018.

16. Gogolyuk P. Mathematical Modeling Of A Synchronous Motor And Centrifugal Pump Combination In Steady State [Electronic resource] / P. Gogolyuk, V. Lysiak, I. Grinberg // IEEE PES Power Systems Conference \& Exposition, 10-13 October 2004, New York City, NY : Conference Publications. 2004. Vol. 3. P. 1444-1448.

17. Kostyshyn, V. S. Simulation of performance characteristics of centrifugal pumps by the electrohydrodynamic analogy method / V. S. Kostyshyn, P. O. Kurlyak // Journal of Hydrocarbon Power Engineering. 2015. Vol. 2, No. 1. P. 24-31.

18. Lysiak V. H. Matematychne modeliuvannia ustalenykh rezhymiv elektropostachalnoi systemy pompovoi stantsii // Tekhnichna elektrodynamika. K., 2008. No. 2. S. 43-50.

19. V. Lysiak, M. Oliinyk. Modeling of Hydraulic Load of Electric Drive in Electrical Complex of Pumping Station. Energy Eng. Control Syst., 2018, Vol. 4, No. 1, pp. 31-36. [in Ukrainian]. 
V. H. Lysiak

Lviv Polytechnic National University, Department of Electric Power Engineering and Control Systems, Vladyslav.H.Lysiak@1pnu.ua

\author{
M. Yo. Oliinyk \\ Lviv Polytechnic National University, \\ Department of Electric Power Engineering and Control Systems, \\ Myhajlo.Ol@gmail.com \\ M. B. Sabat \\ Lviv Polytechnic National University, \\ Department of Electric Power Engineering and Control Systems, \\ Myroslav.B.Sabat@1pnu.ua \\ Y. L. Shelekh \\ Lviv Polytechnic National University, \\ Department of Electric Power Engineering and Control Systems, \\ Yurii.L.Shelekh@1pnu.ua
}

\title{
MODELING OF STEADY-STATE MODES OF THE ELECTRICAL NETWORK FROM THE SYNCHRONOUS ELECTRIC DRIVE OF HYDRAULIC LOADING
}

\author{
(C) Lysiak V. H., Oliinyk M. Yo., Saba M. B., Shelekh Y. L., 2019
}

Pumping stations that provide fluid transportation by pipeline are significant consumers of electricity. Energy overruns due to sub-optimal modes of operation of individual high-power units or sub-optimal number of simultaneously operating less powerful units are quite significant and can have a significant impact on overall energy consumption. Energy overruns at pumping stations also lead to significant overruns in electricity grid elements.

The modes of operation of powerful pumping stations are characterized by a slow change of coordinates over time. In many cases, this makes it possible to reasonably consider such modes as the set of quasi-stationary states that change each other without taking into account the influence of transients. The analysis of the nature of typical modes of pumping units of high-power pumping stations and their power supply systems substantiates the feasibility of isolating the studies of the steady state modes. The overwhelming amount of scientific work devoted to the modeling and analysis of modes of operation of high-power pumping stations concerns asynchronous electric drive pump units. The implementation of prospective controlled synchronous electric drive at pumping stations requires the creation of appropriate research tools.

Conducting full-scale experiments at operating pumping stations is costly, and quite often unacceptable, due to the need to disrupt their continuous functioning during experiments. Therefore, modeling the processes occurring in such objects is in most cases the only possible means of safely investigating them, as well as predicting energy-saving modes and measures. It is shown that the synthesis of energy-efficient steady-state control systems for such objects to improve their energy efficiency is usually not possible without computer simulation of the power unit. A mathematical model of steady state modes of power supply with frequency controlled synchronous electric drive of a centrifugal pump is offered. Using the created model, a number of test calculations of the established modes were performed. The graphical dependences of the basic coordinates on the relative flow rate of the working fluid at the inlet of the pipeline are presented.

Key words: electric network, synchronous motor, reactive power, frequency, pump, performance, pressure, mathematical model. 